\title{
Reference ranges and sources of variability of CD4 counts in HIV-seronegative women and men
}

\author{
M K Maini, R J C Gilson, N Chavda, S Gill, A Fakoya, E J Ross, A N Phillips, \\ I V D Weller
}

\section{Department of Genitourinary Medicine, Camden and Islington Community Health Services NHS Trust, The Middlesex Hospital, London W1N 8AA, UK M K Maini A Fakoya}

Academic Department of Genitourinary Medicine, University College London Medical School, and Camden and Islington Community Health Services NHS Trust, London W1N 8AA, UK R J C Gilson $S$ Gill

E J Ross

A N Phillips

I V D Welle

Department of

Haematology,

University College

London Hospitals

London WC1E 6AU,

UK

N Chavda

Correspondence to: Dr R J C Gilson, Academic Department of Genitourinary Medicine, University College London Medical School,

The Mortimer Market

Centre, Mortimer Market,

Off Capper Street, London

WC1E 6AU, UK.

Accepted for publication

12 September 1995

Background: CD4 lymphocyte counts are used to monitor immune status in HIV disease. An understanding of the variability of CD4 counts which occurs in the absence of HIV infection is essential to their interpretation. The sources and degree of such variability have not been extensively studied.

Objectives: To establish reference ranges for CD4 counts in HIV-seronegative women and heterosexual men attending a genitourinary medicine (GUM) clinic, and to identify possible differences according to gender and cigarette smoking and, in women, any effect of the menstrual cycle, oral contraceptive use and cigarette smoking.

Design: Female and heterosexual male patients attending a GUM clinic and requesting an HIV-antibody test were recruited prospectively. Results from an earlier study of CD4 counts in homosexual men were available for comparison.

Methods: Lymphocyte subpopulation analysis on whole blood by flow cytometry.

Results: The absolute CD4 count and percentage of CD4 cells (CD4\%) were significantly higher in women $(n=195)$ than heterosexual men $(n=91)$ [difference between the means $111 \times$ $106 / 1(95 \%$ CI 41,180$)$ and $3 \cdot 1 \%(1 \cdot 30,4 \cdot 88)]$. The absolute CD4 count and CD4\% were also significantly higher in smokers $(n=143)$ than non-smokers $(n=140)$ [difference $143(79,207)$ and $2 \cdot 1 \%(0 \cdot 43,3 \cdot 81)]$. Reference ranges for absolute CD4 counts (geometric mean $\pm 2 S D$ ) were calculated on log transformed data as follows; female smokers 490-1610, female nonsmokers 430-1350, heterosexual male smokers 380-1600, heterosexual male non-smokers 330-1280. Among other variables examined, combined oral contraceptive pill use was associated with a trend towards a lower absolute CD4 count. Changes were seen in CD4\% with the menstrual cycle. CD4 counts and CD4\% did not differ significantly between heterosexual men and homosexual men $(n=45)$.

Conclusion: There is a significant gender and smoking effect on CD4 counts. The effects of oral contraceptive use and the menstrual cycle warrant further investigation.

(Genitourin Med 1996;72:27-31)

Keywords: CD4 count; reference range; HIV-seronegative

\section{Introduction}

Cohort studies have established the prognostic value of peripheral blood CD4 counts. ${ }^{1-4}$ They are routinely used to assess HIV-related immunosuppression, to decide when to start antimicrobial prophylaxis and antiretroviral therapy, and extensively in clinical trials. However, circulating lymphocytes represent a tiny fraction of the total body lymphoid pool. The majority are in the lymph nodes which are the main sites of HIV replication early in HIV infection. ${ }^{5}$ A functional assessment of CD4 lymphocytes, though not currently routinely available, might provide more information.

Interpretation of the CD4 count requires an understanding of its biological variability and that due to the method of measurement. ${ }^{67}$ The analysis of CD4 counts in HIV-negative populations may help to define this variability.

Heterosexuals, who constitute an increasing proportion of HIV infected patients, have not been extensively studied. Increased percentages of CD4 cells (CD4\%) and absolute CD4 counts in HIV seronegative women compared with heterosexual men have been reported, but these studies have not controlled for potential confounders such as smoking and diurnal variation. ${ }^{8-13}$
We have measured lymphocyte subsets in HIV seronegative women and heterosexual men to identify any difference by gender and any effect of the menstrual cycle, oral contraceptive use and cigarette smoking. The study was designed to minimise the effect of procedural and diurnal variability and to collect data on potential confounders. We have compared the results with those obtained in an earlier, small study of homosexual men.

\section{Methods}

PATIENT POPULATION

We recruited 195 non-pregnant women (median age 27.8 years, range $16 \cdot 8-57 \cdot 7$ ) and 91 heterosexual men (median age 31.4 years, 18.6-66.5) between September 1992 and May 1993. All were attending the genitourinary medicine clinic at The Middlesex Hospital and were requesting an HIV-antibody test with or without other sexually transmitted disease (STD) screening. Only those testing between $9.30 \mathrm{am}$ and $12.30 \mathrm{pm}$ were included.

The study was granted ethical approval and informed consent was obtained. A piloted questionnaire was used to collect demographic and historical data, including menstrual cycle, 
smoking, injecting drug misuse (IDM), and medication (last 3 months). Symptoms and STD test results were recorded.

Forty five homosexual men attending the same clinic (median age 39.5 years, range 22-59) had lymphocyte subsets measured in the same way in 1990. All were repeatedly anti-HIV-seronegative before testing and remained so for more than 6 months after.

\section{Laboratory methods}

Blood was screened for anti-HIV-l and anti-HIV-2 antibodies with an immunometric assay (Wellcozyme 1+2). EDTA samples, held at room temperature, were processed within 6 hours to obtain absolute lymphocyte counts (by automated white cell differential) and lymphocyte subsets. The lysed whole blood staining technique was used with Coulter monoclonals $\mathrm{CD} 2, \mathrm{CD} 19, \mathrm{CD} 4$ and $\mathrm{CD} 8$, conjugated with fluorescein isothiocyanate and phycoerythrin and a dual-colour flow cytometer (Coulter EPICS Profile II). All samples were processed in the haematology laboratory at University College Hospital which participates in a national quality assurance scheme. Correction for decreased lymphocyte purity and monocyte contamination has been evaluated in this laboratory and found to be unnecessary for fresh samples, as used here. Use of the $\mathrm{CD} 4 / \mathrm{CD} 8$ combination of monoclonals results in the inclusion of a small number of CD8 non-T cells, but being weaker staining most are excluded by gating. Their inclusion does not affect the reported results.

Six patients were excluded; one patient with a positive anti-HIV test result, two because of insufficient blood samples and three because of delays before processing or flow cytometer faults.

\section{Statistical methods}

The sample size was calculated to detect a difference of $150 \times 10^{6} / 1 \mathrm{CD} 4$ cells between heterosexual men and women $(80 \%$ power, $5 \%$ significance level). The number of women was increased to maximise the precision of the reference range in this group, and to allow subgroup analyses.

Differences between means (with $95 \%$ confidence intervals) were computed for total lymphocyte counts and lymphocyte subset counts and percent. Un-paired $t$ tests and non-parametric tests were used, but gave equivalent results. Association between variables was sought by multiple linear regression analysis and a dose-response relationship with number of cigarettes smoked by calculation of Spearman's rank correlation coefficient. The

Table 1 Association between gender, smoking, oral contraceptive use, menstrual cycle, ethnic origin, medication, injecting drug misuse, current STD and recent illness and CD4 counts and percent

\begin{tabular}{|c|c|c|c|c|c|c|}
\hline & \multicolumn{3}{|l|}{$C D 4 \%$} & \multicolumn{3}{|c|}{ CD4 absolute count $\times 10^{6} / l$} \\
\hline & Mean & $\begin{array}{l}\text { Difference } \\
\text { in means }\end{array}$ & $\begin{array}{l}(95 \% C I) \\
\text { p value }\end{array}$ & Mean & $\begin{array}{l}\text { Difference } \\
\text { in means }\end{array}$ & $\begin{array}{l}(95 \% C I) \\
\text { p value }\end{array}$ \\
\hline Sex & & \multirow{3}{*}{$3 \cdot 1$} & \multirow{3}{*}{$(1.30,4.88) p=0.001$} & & \multirow{3}{*}{111} & \multirow{3}{*}{$(41,180) p=0.002$} \\
\hline Females $\mathrm{n}=195$ & $47 \cdot 1$ & & & 865 & & \\
\hline $\begin{array}{l}\text { Males } \mathrm{n}=91 \\
\text { Smoking (last } 3 \text { months) }\end{array}$ & $44 \cdot 0$ & & & 754 & & \\
\hline Smoker $n=143$ & $47 \cdot 2$ & \multirow{2}{*}{$2 \cdot 1$} & \multirow{2}{*}{$(0.43,3.81) p=0.014$} & 902 & \multirow{2}{*}{143} & \multirow{2}{*}{$(79,207) \mathrm{p}<0.0001$} \\
\hline $\begin{array}{l}\text { Non-smoker } \mathrm{n}=140 \\
\text { Oestrogen oral contraceptive pill } \\
\text { (last } 1 \text { month) }\end{array}$ & $45 \cdot 1$ & & & 759 & & \\
\hline User $n=54$ & $45 \cdot 8$ & \multirow[t]{2}{*}{$1 \cdot 3$} & \multirow[t]{2}{*}{$(-0.95,3.56) \mathrm{NS}$} & 797 & \multirow[t]{2}{*}{84} & \multirow[t]{2}{*}{$(-1,168) p=0.052$} \\
\hline $\begin{array}{l}\text { Non-user } \mathrm{n}=115 \\
\text { Menstrual cycle phase } \\
\quad \text { (non pill use for }>1 \text { month) }\end{array}$ & $47 \cdot 1$ & & & 881 & & \\
\hline Pre-ovulatory $n=56$ & $48 \cdot 7$ & \multirow{2}{*}{$2 \cdot 4$} & \multirow{2}{*}{$(0.03,4.79) \mathrm{p}=0.047$} & 916 & \multirow{2}{*}{37} & \multirow{2}{*}{$(-68,141) \mathrm{NS}$} \\
\hline $\begin{array}{l}\text { Post-ovulatory } n=59 \\
\text { Menstruating } n=11\end{array}$ & $\begin{array}{l}46 \cdot 3 \\
51 \cdot 4\end{array}$ & & & $\begin{array}{l}879 \\
870\end{array}$ & & \\
\hline $\begin{array}{l}\text { Non-menstruating } \mathrm{n}=104 \\
\text { Ethnic Origin }\end{array}$ & $47 \cdot 1$ & $4 \cdot 3$ & $(0.25,8.31) p=0.038$ & 900 & 30 & $(-147,208) \mathrm{NS}$ \\
\hline Caucasian $n=234$ & $46 \cdot 1$ & \multirow[t]{2}{*}{$0 \cdot 1$} & \multirow[t]{2}{*}{$(-2.99,3.05) \mathrm{NS}$} & 831 & \multirow[t]{2}{*}{1} & \multirow[t]{2}{*}{$(-117,119) \mathrm{NS}$} \\
\hline $\begin{array}{l}\text { Black } \mathrm{n}=25 \\
\text { Medication (any medication taken } \\
\text { in the last } 3 \text { months) } \dagger\end{array}$ & $46 \cdot 0$ & & & 830 & & \\
\hline None $n=204$ & $45 \cdot 9$ & \multirow[t]{2}{*}{$0 \cdot 7$} & \multirow{2}{*}{$(-1 \cdot 25,2 \cdot 63) \mathrm{NS}$} & 828 & \multirow{2}{*}{8} & \multirow{2}{*}{$(-66,83) \mathrm{NS}$} \\
\hline $\begin{array}{l}\text { Any } \mathrm{n}=77 \\
\text { Injecting drug misuse }\end{array}$ & $46 \cdot 6$ & & & 836 & & \\
\hline Never $n=275$ & $46 \cdot 2$ & \multirow[t]{2}{*}{$3 \cdot 8$} & \multirow[t]{2}{*}{$(-0.62,8.18) p=0.09$} & 832 & \multirow[t]{2}{*}{60} & \multirow[t]{2}{*}{$(-111,231) \mathrm{NS}$} \\
\hline $\begin{array}{l}\text { Ever } \mathrm{n}=11 \\
\text { Current STD } \\
\text { No } \mathrm{n}=187\end{array}$ & $42 \cdot 4$ & & & 772 & & \\
\hline $\begin{array}{l}\text { Yes } \mathrm{n}=24 \\
\text { Illness (last } 3 \text { months) }\end{array}$ & $45 \cdot 8$ & 0.06 & $(-3.07,3.19) \mathrm{NS}$ & 880 & 70 & $(-47,194) \mathrm{NS}$ \\
\hline None $n=209$ & $46 \cdot 2$ & 0.05 & $(-2.04,2.14) \mathrm{NS}$ & 816 & 76 & $(-4 \quad 157) n=0.063$ \\
\hline Any $n=62$ & $46 \cdot 3$ & כ & $(204,214) 100$ & 892 & 10 & Jove \\
\hline
\end{tabular}

*Women divided into pre/post-ovulatory, assuming ovulation occurred 14 days before the next anticipated onset of menstruation. Women who had started menstruation within 3 days of recruitment were then analysed separately.

†Treatment last 3 months: antibiotics 49; psychotropics 9; NSAIDs/other analgesics 8.

łCurrent STDs: NSU 12; Chlamydia 5; HSV 2; PID 2; UTI 3 (Candida, BV, warts excluded).

fIllnesses last 3 months: viral/bacterial infection 43 (most upper respiratory tract). 
Table 2 Reference ranges for CD4 percent and absolute counts, CD8 percent and absolute counts, lymphocyte counts and CD4:CD8 ratio

\begin{tabular}{|c|c|c|c|c|c|c|}
\hline & \multicolumn{2}{|l|}{$\begin{array}{l}\text { CD4 } \\
\text { geometric mean } \\
\text { ( } \pm 2 \text { standard } \\
\text { deviations) }\end{array}$} & \multicolumn{2}{|l|}{$\begin{array}{l}\text { CD8 } \\
\text { geometric mean } \\
\text { ( } \pm 2 \text { standard } \\
\text { deviations) }\end{array}$} & \multirow{2}{*}{$\begin{array}{l}\text { Lymphocytes } \\
\text { geometric mean } \\
\text { ( } \pm 2 \text { standard } \\
\text { deviations) }\end{array}$} & \multirow{2}{*}{$\begin{array}{l}\text { CD4:CD8 } \\
\text { geometric mean } \\
\text { ( } 2 \text { standard } \\
\text { deviations) }\end{array}$} \\
\hline & $\%$ & Absolute count & $\%$ & Absolute count & & \\
\hline \multicolumn{7}{|l|}{ Total } \\
\hline Men $\mathrm{n}=91$ & $43 \cdot 3(30 \cdot 4-61 \cdot 6)$ & $710(350-1440)$ & $27 \cdot 0(15 \cdot 9-45 \cdot 8)$ & $440(200-1000)$ & $1.6(0.9-2.9)$ & $1 \cdot 6(0 \cdot 7-3 \cdot 4)$ \\
\hline $\begin{array}{l}\text { Women } \mathrm{n}=195 \\
\text { Non-smokers }\end{array}$ & $46 \cdot 6(34 \cdot 9-62 \cdot 1)$ & $820(450-1510)$ & $26 \cdot 0(16 \cdot 7-40 \cdot 6)$ & $460(230-910)$ & $1.8(1 \cdot 1-3 \cdot 0)$ & $1 \cdot 8(1 \cdot 0-3 \cdot 3)$ \\
\hline Men $n=49$ & $42 \cdot 6(29 \cdot 5-61 \cdot 6)$ & $650(330-1280)$ & $26 \cdot 7(15 \cdot 0-47 \cdot 5)$ & $410(170-1000)$ & $1.5(0.9-2.7)$ & $1 \cdot 6(0 \cdot 7-3 \cdot 6)$ \\
\hline Women $\mathrm{n}=91$ & $45.6(34 \cdot 4-60 \cdot 5)$ & $760(430-1350)$ & $26 \cdot 2(17 \cdot 4-39 \cdot 6)$ & $440(230-830)$ & $1.7(1 \cdot 0-2 \cdot 8)$ & $1 \cdot 7(1 \cdot 0-3 \cdot 1)$ \\
\hline Men $n=41$ & $44 \cdot 3(31 \cdot 6-62 \cdot 1)$ & $780(380-1600)$ & $27 \cdot 2(17 \cdot 0-43 \cdot 8)$ & $480(240-960)$ & $1 \cdot 8(1 \cdot 0-3 \cdot 2)$ & $1 \cdot 6(0 \cdot 8-3 \cdot 3)$ \\
\hline Women $\mathrm{n}=102$ & $47 \cdot 6(35 \cdot 8-63 \cdot 4)$ & $890(490-1610)$ & $25 \cdot 7(16 \cdot 0-41 \cdot 5)$ & $480(240-970)$ & $1.9(1 \cdot 1-3 \cdot 0)$ & $1.8(0.9-3.6)$ \\
\hline
\end{tabular}

distribution of lymphocyte subset counts was skewed to the right and the data were therefore transformed to the log scale for the calculation of reference ranges (geometric mean \pm twice the standard deviation); other analyses were not sensitive to log transformation, and therefore untransformed data was used.

\section{Results}

Women had significantly higher CD4 counts and $\mathrm{CD} 4 \%$ than heterosexual men (table 1 ). For CD $4 \%$ the difference in the means was $3 \cdot 1(47 \cdot 1$ versus $44 \cdot 0 \%)$ and for CD4 count the difference was $111 \times 10^{6} / 1$ (865 versus $\left.754 \times 10^{6} / 1\right)$. No association was found with age although $85 \%$ of the patients fell within the age range of 20-40 years (data not shown). Smokers had significantly higher CD4 counts and CD4\% than non-smokers. There was a positive dose-response relationship with the number of cigarettes smoked (Spearman's rank correlation coefficient $0 \cdot 17, p=0.04$; data not shown).

Use of any form of hormonal contraception in the preceding 3 months had no significant effect on CD4 counts; however, among current (in the last month) users of oestrogencontaining oral contraceptive pills (OCPs) there was a trend $(p=0.052)$ towards a lower CD4 count but not CD4\%.

An effect of the menstrual cycle was sought, after excluding women using hormonal contraception, those with erratic cycles and the post-menopausal $(n=80)$. Pre-ovulatory women ( $\mathrm{n}=56)$ had higher CD4\% than post-ovulatory women ( $\mathrm{n}=59, \mathrm{p}=0.047$ ). Further analysis showed that women who were menstruating $(\mathrm{n}=11)$ had higher $\mathrm{CD} 4 \%$ than others $(n=104, p=0.038)$, but those within 2 days of ovulating did not differ significantly (data not shown). There were no significant differences in absolute CD4 counts.

Gender, smoking and recent illness showed significant associations with CD4 count after adjusting for other variables in a multiple linear regression model, suggesting that they act independently. The adjusted differences in mean $\mathrm{CD} 4$ count indicate the strongest association was with smoking $\left(142 / \mathrm{mm}^{3}\right.$ higher in smokers; $p=0.0001$ ), followed by gender $\left(108 / \mathrm{mm}^{3}\right.$ higher in females; $\left.\mathrm{p}=0.002\right)$, and recent illness $\left(80 / \mathrm{mm}^{3}\right.$ higher if recent illness, $p=0.04)$. When oestrogen oral contraceptive use was included in a model fitted for women only, the difference in mean CD4 count was $66 / \mathrm{mm}^{3}$ (higher in non-pill users; $\mathrm{p}=0 \cdot 13$ ). There were no statistically significant interaction effects observed. The $\mathrm{R}$-square value for the multiple linear regression model was $0 \cdot 12$, indicating that these variables can only explain a small proportion of all inter-individual variability in CD4 counts.

Similar analyses were conducted for CD8 counts and $\mathrm{CD} 8 \%$, lymphocyte counts and CD4:CD8 ratio (data not shown). There were significant associations between total lymphocyte counts and CD8 counts and smoking, and between $\mathrm{CD} 8$ counts, $\mathrm{CD} 8 \%$ and CD4:CD8 ratio and menstruation. There were no gender differences in CD8 counts, $\mathrm{CD} 8 \%, \mathrm{CD} 4: \mathrm{CD} 8$ ratio or total lymphocyte count.

Table 2 shows the reference ranges calculated for male and female non-smokers and smokers for $\mathrm{CD} 4 \%$ and absolute counts, CD8\% and absolute counts, total lymphocyte counts and CD4:CD8 ratios.

The mean CD4 count and CD4\% in the group of 45 homosexual men tested in 1990 (mean CD4 count $830, \mathrm{CD} 4 \% 44.3$ ) were not significantly different from the heterosexual men in this study. The reference range for CD4 counts was $420-1510 \times 10^{6 / 1}$ and for CD4\% 32:1-59.9.

\section{Discussion}

This study of HIV-seronegative GUM clinic attenders confirms that CD4 counts are significantly higher in women than heterosexual men after controlling for other sources of variability. Bofill et $a l^{8}$ found that seronegative women had $\mathrm{CD} 4$ counts that were $28 \%$ higher, but a disproportionate number of the women were tested in the afternoon, so the gender difference might have been attributable to diurnal variation. Several studies have reported the same gender difference, but have not controlled for other factors including smoking, ${ }^{891213}$ pregnancy, ${ }^{811}$ intercurrent infections, ${ }^{8911}$ ethnicity, ${ }^{1213}$ or HIV status. ${ }^{91213}$

Procedural factors affect the reliability of lymphocyte subset counts. In this study all samples were kept at room temperature until the total lymphocyte count was measured by automated counter in a single laboratory, within 6 hours. In other studies the procedure was either not specified ${ }^{914}$ or was not uniform ${ }^{8}$ leading to only $\mathrm{CD} 4 \%$ being reported. ${ }^{1011}$ 
Flow cytometry is more reproducible than manual fluorescence as used in other studies $^{1516}$ and whole blood staining eliminates prior lymphocyte separation, a potential source of cell loss..$^{912-1417}$

CD4-lymphocyte counts exhibit circadian variation of up to $60 \%$ with the nadir at about $11.00 \mathrm{am}^{1518}$ In this study all samples were taken between $9.30 \mathrm{am}$ and $12.30 \mathrm{pm}$. Circannual variability in $\mathrm{CD} 4 \%$ has been reported, with higher levels in April $^{19}$ and October/November, ${ }^{19}{ }^{20}$ but no such effect was seen in the present study (data not shown). $\mathrm{CD} 4 \%$ has been shown to increase with age by $1 \%$ per decade, ${ }^{9-11}$ but no such effect was detectable in this study. As reported previously $^{921}$ there were no racial differences in CD4 counts, although our study population was largely Caucasian.

Smoking is associated with a leucocytosis, a lymphocytosis and an increase in CD4\% and CD4 absolute counts. ${ }^{172223}$ This was confirmed here and shown to be independent of gender. There was a dose-response effect of smoking, consistent with previous reports ${ }^{17} 23$ and reports of reversibility of the effect in ex-smokers. ${ }^{172}$ These findings strengthen the evidence for a causal relationship.

We included only patients who were tested HIV-antibody negative. Although $29 \%$ of the heterosexuals had had unprotected intercourse in the 3 months prior to testing, the chance of any of them being in the seroconversion window period is very small, given the overall prevalence of HIV of one in 286 recruits. None had a history of other serious illness associated with CD4 lymphopaenia. ${ }^{24-27}$ No significant association was found between CD4 counts and the presence of an STD diagnosed at the time, although the number of patients was small. As expected, there was an association between other recent illness, most commonly upper respiratory tract infections, and an increase in CD4 count.

Treatment with cyclophosphamide or prednisolone has been associated with a decrease in CD4 counts, ${ }^{28}$ but in this study no association with medication was observed. Only 11 patients had a history of injecting drug misuse; however, there was a trend $(p=0.09)$ towards them having a lower CD4\%. We found no difference in either CD4 counts or CD4\% between heterosexual men and the group of homosexual men tested in 1990.

One possible explanation for the observed gender difference in CD4 counts is a sex hormone effect. Circulating lymphocytes have receptors for androgens and oestrogens, ${ }^{29}$ and these hormones also exhibit diurnal and circannual rhythmicity. ${ }^{16} 190$ If the adult female pattern of hormones is responsible for the difference in CD4 counts, the gender difference might be expected to appear at puberty. Tollerud $e t$ al found a gender difference in 17-19 year olds, but not in 12-16 year olds. ${ }^{14}$ In adults under 40 years or age, Ohta et $a l^{13}$ found higher CD4 counts in women than in men, but no difference in those over 40. A small study ${ }^{31}$ found that hormone replacement therapy had no effect on $\mathrm{CD} 4$ counts in post-menopausal women. Changes in CD4 count and CD4\% have been observed in pregnant women, ${ }^{32}$ who were therefore excluded from our study.

A previous small study found that the menstrual cycle and OCP use had no effect on $\mathrm{CD} 4 \%$ but did not control for other variables. ${ }^{33}$ Our results suggest that OCP users may have lower CD4 counts and menstruation may be associated with higher CD4\%.

Interestingly, although several factors have been shown to be associated with CD4 count variability in this study, these factors still only account for a small proportion of the variability observed (R-square $0 \cdot 12$ ). Other influences still need to be sought.

The calculated reference ranges for CD4\% may be more stable than CD4 count, since the total lymphocyte count used to calculate the CD4 absolute count shows considerable variability, both within an individual and between laboratories. ${ }^{34} \mathrm{CD} 4 \%$ may be a better prognostic guide than the absolute count. ${ }^{35} 36$

Knowledge of $\mathrm{CD} 4$ count reference ranges is essential in assessing the degree of immunosuppression in HIV-positive, asymptomatic individuals. A CD 4 count of $500 \times 10^{6} / 1$ has been regarded as a clinically significant level, below which antiretroviral therapy should be started. The data here show that the reference range of CD4 counts extends well below 500 . Awareness of the factors influencing counts and the potential magnitude of their effect should help in interpreting CD4 count changes and designing clinical trials. However, findings in HIV-seronegatives cannot be directly extrapolated to HIV-seropositives. For example, the effect of smoking on CD4 counts may be attenuated within 2 years after HIVseroconversion ${ }^{23} 37$ by a more rapid decline in CD4 counts in the HIV-infected smokers. ${ }^{23}$ Diurnal variation may also be reduced in HIV seropositives. ${ }^{34} 38$

The gender difference observed in seronegatives may also be lost in seropositives. Women may have a faster decline in CD4 count following HIV infection. ${ }^{39}$ Alternatively, HIVinfected women may have higher circulating CD4 counts than men but this may not have any functional significance. If this were true, they would develop opportunistic infections at higher counts; recent evidence is against this (AC Lepri, personal communication).

Whether the rate of progression to symptomatic HIV-disease and AIDS is the same in HIV-infected men and women is uncertain. If disease progression were slower in women, this would be consistent with a higher pre-infection CD4 count being associated with slower progression to AIDS. ${ }^{40}$ Testing such hypotheses is hindered by the need to control for the other factors affecting disease progression.

We gratefully acknowledge the financial support of the AIDS Education and Research Trust (AVERT), and Camden and Islington Community Health Services NHS Trust. We thank
Professor S J Machin and Mr Alan Carter, Department of Haematology, UCLH, for the help with the lymphocyte subset Haematology, UCLH, for the help with the lymphocyte subset
analyses and Professor R S Tedder, Division of Virology, UCLMS, for the HIV serology. 
1 Fahey J, Taylor JMG, Detels R, et al. The prognostic value of cellular and serological markers in infection with human immunodeficiency virus type $1 . N \mathrm{Engl} \mathcal{f} \mathrm{Med}$ 1990;322:166-72

2 Stites DP, Moss AR, Bacchetti P, et al. Lymphocyte subset analysis to predict progression to AIDS in a cohort of homosexual men in San Francisco. Clin Immuno Immunopathol 1989;52:96-103.

3 Phillips AN, Lee CA, Elford J, et al. Serial CD4 lymphocyte counts and development of AIDS. Lancet 1991;337: 389-92.

4 Phair J, Muñoz A, Detels R, Kaslow R, Rinaldo C, Saah A and the Multicenter AIDS Cohort Study Group. The risk of Pneumocystis carinii pneumonia among men risk of Pneumocystis carinit pneumonia among men infected with human immun

5 Pantaleo G, Graziosi C, Fauci AS. The immunopathogenesis of human immunodeficiency virus infection. $N$ Engl $\mathcal{F}$ Med 1993;328:327-35.

6 Bird AG. Monitoring of lymphocyte subpopulation changes in the assessment of HIV infection. Genitourin Med 1990;66:133-7.

7 Lawrence J. T-cell subsets in health, infectious disease and idiopathic CD4+ T lymphocytopenia. Ann Intern Med 1993;119:55-62.

8 Bofill M, Janossy G, Lee CA, et al. Laboratory control values for CD4 and CD8 $\mathrm{T}$ lymphocytes. Implications for HIV-I diagnosis. Clin Exp Immunol 1992;88:243-52.

9 Tollerud DJ, Clark JW, Morris Brown L, et al. The influence of age, race and gender on peripheral blood mononuclear-cell subsets in healthy non-smokers. $\mathcal{f}$ Clin Immunol 1989;9:214-22.

10 Parker JW, Adelsberg B, Azen SP, et al. Leukocyte immunophenotyping by flow cytometry in a multisite study: standardisation, quality control and normal values in the Transfusion Safety Study. Clin Immunol Immunopathol 1990;55:187-220.

11 Reichert $T$, DeBruyère $M$, Deneys $V$, et al. Lymphocyte subset reference ranges in adult Caucasians. Clin Immunol Immunopathol 1991;60:190-208.

12 Goto $M$, Nishioka $K$. Age and sex-related changes of the lymphocyte subsets in healthy individuals: an analysis by two-dimensional flow cytometry. $\mathcal{f}$ Gerontol 1989;44: two-dim.

13 Ohta Y, Fujiwara K, Nishi T, Oka H. Normal values of peripheral lymphocyte populations and $T$ cell subsets at a fixed time of day: a flow cytometric analysis with monoclonal antibodies in 210 healthy adults. Clin Exp Immunol 1986;64:146-9.

14 Tollerud DJ, Ildstad ST, Morris Brown L, et al. T-cell subsets in healthy teenagers: transition to the adult phenotype. Clin Immunol Immunopathol 1990;56:88-96.

15 Levi FA, Canon C, Blum JP, Mechkouri M, Reinberg A, Mathe G. Circadian and/or circahemidian rhythms in nine lymphocyte-related variables from peripheral blood of healthy subjects. F Immunol 1985;134:217-22.

16 Levi FA, Canon C, Touitou Y, et al. Circadian rhythms in circulating $\mathrm{T}$-lymphocyte subtypes and plasma testoscirculating T-lymphocyte subtypes and plasma testosterone, total and free cortisol

17 Tollerud DJ, Clark JW, Morris Brown L, et al. The effects of cigarette smoking on $\mathrm{T}$ cell subsets. A populationbased survey of healthy Caucasians. Am Rev Respir Dis 1989;139:1446-51.

18 Ritchie AWS, Oswald I, Spedding Micklem H, et al. Circadian variation of lymphocyte subpopulations: a study with monoclonal antibodies. $B M \mathcal{F} 1983 ; 286$ : 1773-5.

19 Levi FA, Canon C, Touitou Y, Reinberg A, Mathé G. Seasonal modulation of the circadian time structure of circulating $T$ and Natural Killer lymphocyte subsets from circulating T and Natural Killer lymphocyte subse

20 Van Rood Y, Goulmy E, Blokland E, Pool J, Van Rood J, Van Houwelingen H. Month-related variability in immunological test results; implications for immunologica follow-up studies. Clin Exp Immunol 1991;86:349-54.
21 Gorter RW, Vranizan KM, Osmond DH, Moss AR. Differences in laboratory values in HIV infection by sex, race and risk group. AIDS 1992;6:1341-7.

22 Hughes DA, Haslam PL, Townsend PJ, Turner-Warwick $M$. Numerical and functional alterations in circulating lymphocytes in cigarette smokers. Clin Exp Immunol 1985;61:459-66.

23 Royce R, Winkelstein W. HIV infection, cigarette smoking and CD4 T-lymphocyte counts: preliminary results from the San Francisco Men's Health Study. AIDS 1990;4 327-33.

24 Beck JS, Potts RC, Kardjito T, Grange JM. T4 lymphopenia in patients with active pulmonary tuberculosis. Clin Exp Immunol 1985;60:49-54.

25 Williams RC, Koster FT, Kilpatrick KA. Alterations in lymphocyte cell surface markers during various human infections. $A m \mathcal{F}$ Med 1983;75:807-16.

26 Syriälä H, Surcel HM, Ilonen J. Low CD4/CD8 T lymphocyte ratio in acute myocardial infarction. Clin Exp Immunol 1991;83:326-8.

27 Lewis DE, Gilbert BE, Knight V. Influenza virus infection induces functional alterations in peripheral blood lymphocytes. F Immunol 1986;137:3777-81.

28 Bast RC, Reinherz EL, Maver C, Lavin P, Schlossman SF. Contrasting effects of cyclophosphamide and prednisolone on the phenotype of human peripheral bredleukocytes. Clin Immunol Immunopathol 1983;28: 101-14.

29 Grossman CJ. Interactions between the gonadal steroids and the immune system. Science 1985;227:257-60.

30 Reinberg A, Lagoguey M, Cesselin F, et al. Circadian and circannual rhythms in plasma hormones and other variables of five healthy young human males. Acta Endocrinologica 1978;88:417-27.

31 Manyonda IT, Pereira RS, Makinde V, Brincat M, Varma RT. Effect of 17 beta-oestradiol on lymphocyte subpopulations, delayed cutaneous hypersensitivity responses and mixed lymphocyte reactions in post-menopausal women. Maturitas 1992;14:201-10.

32 Biggar RJ, Pahwa S, Minkoff $\mathrm{H}$, et al. Immunosuppression in pregnant women infected with human immunodeficiency virus. Am $f$ Obstet Gynaecol 1989;161: deficiency

33 Coulam CB, Silverfield JC, Kazmar RE, Garrison Fathman C. T-lymphocyte subsets during pregnancy and the menstrual cycle. Am $\mathcal{F}$ Reprod Immunol 1983;4:88-90.

34 Malone JL, Simms TE, Gray GC, Wagner KF, Burge JR, Burke DS. Sources of variability in repeated T-helper lymphocyte counts from human immunodeficiency virus type l-infected patients: total lymphocyte count fluctuations and diurnal cycle are important. $\mathcal{F}$ Acquir Immune Defic Syndr 1990;3:144-51.

35 Burcham J, Marmor M, Dubin N, et al. CD4\% is the best predictor of development of AIDS in a cohort of HIVinfected homosexual men. AIDS 1991;5:365-72.

36 Taylor JMG, Fahey JL, Detels R, Giorgi JV. CD4 percentage, CD4 number and CD4:CD8 ratio in HIV infection: which to choose and how to use. $\mathcal{f}$ Acquir Immune Defic Syndr 1989;2:114-24.

37 Burns DN, Kramer A, Yellin F, et al. Cigarette smoking: a modifier of human immunodeficiency virus type 1 infection? $\mathcal{F}$ Acquir Immune Defic Syndr 1991;4:76-83.

38 Martini E, Muller JY, Doinel C, et al. Disappearance of CD4-lymphocyte circadian cycles in HIV-infected patients: early event during asymptomatic infection. AIDS 1988;2:133-4.

39 Levin LI, Chung RC, Milazzo M, Brundage JF and the Military Medical Consortium for Applied Antiretroviral Research. Preliminary analysis: comparison of HIV-I disease progression between men and women who are clinically evaluated in US Army medical centers. IXth International Conference on AIDS, Berlin, June 1993 International Conferen

40 Phillips A, Lee CA, Elford J, Janossy G, Kernoff PBA. Monitoring CD4 counts in HIV infection (letter). Lancet 1991;337:1108-9. 